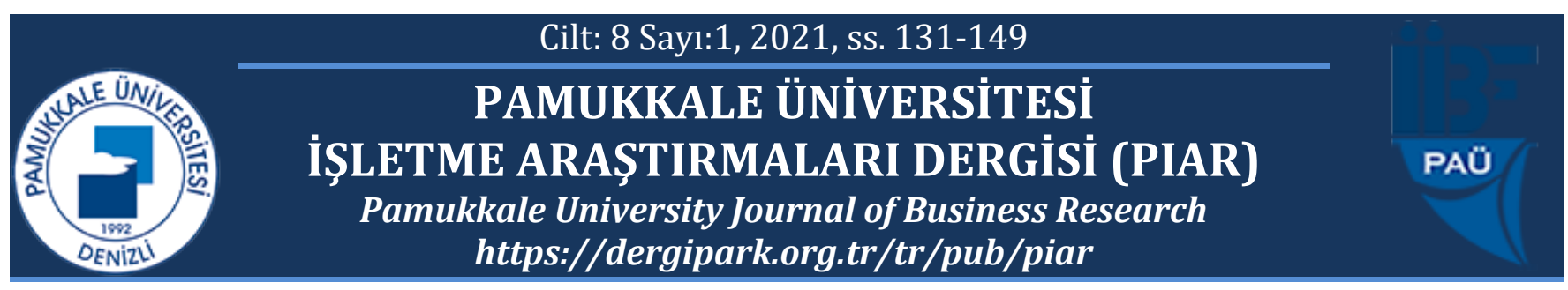

\title{
İtfaiye Erlerinin Vardiya Çizelgeleme Sorununun Çözümünde Tamsayılı Programlama Yaklaşımı*
}

\author{
Integer Programming Approach For Solution of Fire Fighters Schedule \\ Problems
}

\begin{abstract}
Ali KATRANCI ${ }^{*}$
Arzu ORGAN ${ }^{2}$

${ }^{1}$ Pamukkale Üniversitesi, SBE, akatrancii@gmail.com, https://orcid.org/0000-0002-7586-1169

${ }_{2}^{2}$ Pamukkale Üniversitesi, İ̈BF, İşletme, aorgan@pau.edu.tr, https://orcid.org/0000-0002-2400-4343

* Yazışılan Yazar/Corresponding author
\end{abstract}

\section{Öz}

Günümüzde hem özel sektörde hem de kamu sektöründe birçok kurum ve kuruluş vardiya usulüne göre çalışmaktadır. Bu kurum ve kuruluşlarda çalışan personellerin verimli bir şekilde faaliyetlerini sürdürebilmeleri için vardiyalarının etkin bir biçimde planlanması gerekmektedir. Etkin bir biçimde planlanmayan vardiyalarda çalışan personellerde, uyku bozukluğu, yorgunluk, kanser, kalp ve damar hastalıkları, ailevi ve psikolojik problemler gibi sorunlar meydana gelebilmektedir. Bu tür sorunları ortadan kaldırmak amacıyla, çalışanların vardiyalarının etkin bir şekilde planlanması gerekmektedir. Ayrıca, çalışan personelin isteklerini dikkate alarak oluşturulan planlamalar, işyerinde verimlilik artışı ve rekabet avantajı să̆lanması beklenir. Bu çalışmada itfaiye teşkilatında çalışan itfaiye erlerinin vardiya planlama problemi ele alınmıştır. Planlanmanın çözümü için tamsayılı programlama modeli oluşturulmuş ve oluşturulan model GAMS paket programı ile çözülmüştür. Bu yöntem ile birlikte itfaiye erlerinin ve idarenin istekleri tam yerine getirilmiş ve optimal sonuca ulaşılmıştır.

Anahtar kelimeler: Vardiya Planlaması, Tamsayıl Programlama, Ittfaiye Teşkilatı

JEL kodları: C61, C44, M12

\begin{abstract}
Nowadays, a lot of organizations and institutions both in private and public sectors operate on a shift basis. For the personnel employed in these organizations and institutions perform their tasks in a productive manner, their shifts must be planned efficiently. Problems such as sleep disorder, fatigue, cancer, heart, and vascular diseases, as well as domestic and psychological problems may emerge for the personnel working shifts that have not been planned efficiently. In order to eliminate such problems, employees' departments need to be actively planned. In addition, it is expected that the plans created by taking into consideration the requests of the working personnel provide productivity increase and competitive advantage in the workplace. In this study, the problem of scheduling for the fire fighters working at the fire department is discussed. For the solution of scheduling, integer programming model is formed, and this model is solved using GAMS software. With this method, all the requests from both the fire fighters and the administration are fulfilled and an optimal result is achieved.
\end{abstract}

Keywords: Shift Scheduling, Integer Programming, Fire Fighter

JEL codes: C61, C44, M12

\footnotetext{
*Bu çalışma Ali Katrancı'nın “Tamsayılı Programlama Tekniği ile Vardiya Planlaması: İtfaiye Teşkilatı Örneği” başlıklı Yüksek Lisans Tez'inden türetilmiştir.
} 


\section{GİRIŞ̧}

Vardiyalı çalışma sistemi, günümüzde çalışma hayatının dinamikliği ve üretimde makineleşmenin artması ile başta endüstri ve hizmet sektörü olmak üzere çeşitli sektörlerde yaygın bir şekilde kullanılmaya başlanmıştır (Akyol Güner, 2010: 1). Bu çalışma sistemi ile kesintisiz bir şekilde üretimin gerçekleştirildiği süreçlerde çalışan personeller için bir çalışma planı yapılarak, çalışanların memnuniyetinin sağlanıp verimliliğin arttırılması, işletme giderlerinin azaltılması, üretim ya da hizmet için gerekli olan sürenin azaltılması gibi konularda iyileştirmeler yapılabilir (Varlı ve Eren, 2017: 186).

Vardiyalı çalışma sistemi, 7 gün 24 saat süresince kesintisiz bir şekilde üretimin devam ettiği sağlık, eğlence, güvenlik, hizmet gibi sektörlerde yaygın bir şekilde kullanılmaktadır. 7 gün 24 saat kesintisiz çalışmanın gerektirdiği sektörlerden birisi de itfaiye teşkilatıdır. Yangınları söndürmek amacıyla oluşturulan itfaiye teşkilatı günümüzde bu görevinin yanında doğal afetler sonucunda meydana gelen durumlarda arama ve kurtarma çalışmalarını gerçekleştirmek, ilk yardım hizmetlerini sağlamak, su baskınlarına müdahale etmek, kaza, çökme, patlama, mahsur kalma gibi durumlara müdahale etmek gibi görevlere sahiptirler. $\mathrm{Bu}$ görevler kesintisiz bir süreç gerektirdiğinden dolayı vardiyalı çalışmayı gerekli kılmaktadir.

Bu çalışmada öncelikle hem kamu hem de özel sektörde faaliyet gösteren çeşitli kurum ve kuruluşlar tarafından tercih edilen vardiyalı çalışma sistemi hakkında bilgilere yer verilmiştir. Ayrıca bu bölümde çeşitli kurum ve kuruluşların vardiyalı çalışma sistemini tercih etme sebepleri, vardiyalı çalışma sistemin uygulanması ile meydana gelebilecek sorunlar ve literatürde yapılan çalışmalara yer verilmiştir. Daha sonra, uygulamada kullanılan tamsayılı programlama tekniği ile ilgili teorik bilgilere yer verilmiştir. Çalışmanın uygulama bölümünde, 7 gün 24 saat kesintisiz bir şekilde çalışmalarına devam eden itfaiye erlerinin vardiya problemi ele alınmıştır. Ele alınan problem GAMS paket programı kullanılarak optimal çözüme ulaştırılmıştır. Bu çalışma literatürde itfaiye erlerinin vardiyalarının planlanması amacıyla gerçekleştirilen az sayıda çalışma olması, hem itfaiye istasyonu hem de itfaiye erlerinin isteklerini dikkate alması dolayısıyla literatüre katkısı olacağ 1 düşünülmektedir.

\section{VARDİYALI ÇALIŞMA SISTEMİ}

Vardiyalı çalışma sistemi, temeli Romalılar Dönemine kadar uzanan ve Sanayi Devrimi ile yaygın bir kullanım alanına sahip olan bir çalışma sistemidir (Kazancı Yabanova, 2016: 4). İlk kez yüksek sıcaklıktaki fırınların çalışmasına uyum sağlamak amacıyla demir çelik sektöründe uygulanmıştır (Koruca, 2010: 470).

18. yüzyılda buharın keşfedilmesiyle başlayan Sanayi Devrimi hem toplum yapısında hem de çalışma yaşamında çeşitli değişiklikler meydana getirmiştir. Bu doğrultuda, kadın ve çocuklar başta olmak üzere birçok kişi çeşitli el dokuma atölyelerinde ve maden ocaklarında 18 saate kadar varan çalışma süreleri ile çalışmaya başlamışlardır. Bu uzun çalışma süreleri, çeşitli sakatlıkların yaşanmasına ve erken yaşta ölümlere sebep olmuştur (Kazancı Yabanova, 2016: 4).

19. yüzyıla gelindiğinde ise günlük çalışma sürelerinin uzunluğu başta İngiltere, Fransa ve Almanya' da bulunan parlamentoların, bilim insanlarının, sendikaların ve çeşitli sivil toplum 
örgütlerinin tartıştıkları bir konu haline gelmiştir (Dinçer, 2006: 82). Sanayi Devrimi ile başlayan ve günün neredeyse üçte ikisini kapsayan uzun çalışma sürelerinin, çalışanlarda başta sağlık sorunları olmak üzere çeşitli psikolojik, ailevi ve toplumsal sorunlar yaşanması bu tartışmaların nedeni olarak gösterilebilir.

Uzun çalışma saatleri boyunca çalışanlarda meydana gelen problemleri ortadan kaldırabilmek amacıyla çeşitli girişimlerde bulunulmuş ve bu girişimlerden ilki de 1833 yılında İngiltere'de fabrika çalışanlarının çalışma koşullarının iyileştirilmesi ve belli saatler arasında çalışılmasını gerekli kılan "Factroy Act" yasasıdır. Ayrıca bu yasaya uymayanlara para cezaları da uygulanmıştır (Pekşen Arı, 2013: 3).

Uzun çalışma sürelerinin meydana getirdiği problemleri ortadan kaldırabilmek amacıyla uygulanan ikinci girişim ise, 1847 yılında İngiltere'de çıkarılarak kadın ve çocukların günlük çalışma sürelerini 10 saate kadar düşüren “On saatlik İşgücü Kanunu ”dur. Diğer bir girişim ise, 1871 yılında çıkarılarak tüm sanayi kuruluşlarında çalışma süresini 10,5 saat olarak belirleyen kanundur (İncir, 1998: 17).

1900'lü yıllarda vardiyalı çalışma sistemi ile çalışanlarda meydana gelen problemleri ortadan kaldırmak amacıyla uluslararası kanunlarda da önemli değişiklikler meydana gelmiştir. 1990 yılında Uluslararası Çalışma Örgütü (ILO) tarafından çalışma saatleri ile ilgili olarak yeni standartlar getirilmiş, 1993 yılında da vardiya ve dinlenme zamanlarına yönelik olarak Avrupa Çalışma Saatleri Standartları oluşturulmuştur (Pekşen Arı, 2013: 4).

ILO'nun çalışma yaşamında getirdiği düzenlemeler ile yaygın bir şekilde kullanılmaya başlayan vardiyalı çalışma sistemi üzerinde uzlaşılmış bir tanım olmaması ile birlikte, çok yaygın bir şekilde bilinerek çalışılan bir iş örgütlenme tekniği olarak tanımlanabilir (Bambra vd., 2008: 427). Bir başka tanıma göre vardiyalı çalışma sistemi, çalışmanın en az yarısının 8.00-16.00 saatleri arasında olmayan bir zaman diliminde yapılmasinı gerektiren standart dışı zaman çizelgesidir (Pease ve Raether, 2003: 1). Diğer bir tanıma göre, işin faaliyet alanına göre değişiklik göstermesine bağlı olarak başlangıç ve bitiş sürelerinin sabah, akşam ve gece çalışmaları olarak düzenlenmesidir (Yüksel, 2002: 199).

Teknolojik bir gereklilik olarak ortaya çıkabileceği gibi bazen de topluma faydalı olmak amacıyla da yaygın bir şekilde kullanılan vardiyalı çalışma sistemi (Arpacı, 2007: 72), telefon şirketleri, havayolları, hastaneler, güvenlik hizmetleri, bankalar, enerji dağıtım hizmetleri, sağlık hizmetleri, oteller, mağazalar, eğlence merkezleri gibi kesintisiz hizmet veren yerlerde yaygın bir şekilde başvurulan bir çalışma sistemidir (Pati vd., 2001: 32, Dinçer, 2006: 77).

Vardiyalı çalışma sistemi ile çalışmayı gerektiren çeşitli nedenler olmakla birlikte genel olarak bu nedenleri ekonomik nedenler, sosyal nedenler ve sosyo-politik nedenler olmak üzere 3 ana grupta incelenebilir (Yüksel, 2006: 9).

Ekonomik nedenler, vardiyalı çalışma sistemi ile çalışmayı gerektiren en önemli sebeplerdir. Çünkü makinalardan daha çok yararlanmak, üretim miktarını arttırarak ürün başına düşen genel giderleri ve birim ürün maliyetini azaltmak ve böylece rekabet şansını yakalamak, verimliliği attırmak, atıl kapasiteyi değerlendirmek, yatırım sermayesini artırmak gibi nedenler gösterilebilir (Dinçer, 2006, 77). İşletmeler açısından karlı bir durum olan vardiyalı çalışma sistemi, çalışanlar tarafından da yaygın bir şekilde tercih edilmektedir. Bunun en önemli nedeni de daha fazla para kazanma istediğidir (Gerz, 2017: 44). 
Vardiyalı çalışma sistemini gerekli kılan ikinci neden ise sosyal nedenlerdir. Toplumun istek ve ihtiyaçlarının 7 gün 24 saat karşılanması amacıyla faaliyet gösteren başta sağlık hizmetleri olmak üzere güvenlik hizmetleri, itfaiye teşkilatı, fırınlar, matbaalar, eğlence işletmeleri gibi sektörlerde vardiyalı çalışma sistemi tercih edilmektedir.

Vardiyalı çalışma sistemini gerektiren üçüncü neden ise sosyo-politik nedenlerdir. Sosyopolitik nedenler, vardiyalı çalışma sistemiyle daha fazla kişiyi istidam etme dolayısıyla da işsizlik sorununa çözüm bulmak için tercih edilmektedir.

Geleneksel çalışma saatlerinin dişında çalışmaları içeren vardiyalı çalışma sisteminde (Hung vd., 2016: 1045) her bir ekip işletmenin kurallarına ve yasalara bağlı olarak belli saatlerde çalışmaktadır. Bu süre sonunda da ekip işi yeni gelen ekibe devretmektedir. Bu şekilde, bir işyerinde birden fazla grup işleri kendi çalışma süreleri içerisinde yerine getirmektedir. Böylece, 24 saat boyunca mal ve hizmet üretimi devam etmektedir. İşçi sayısının çok olduğu büyük işletmelerde uygulanan bu sistem, genel olarak sabit vardiya sistemi ve dönüşümlü vardiya sistemi olarak 2'ye ayrılmaktadır.

Sabit vardiya sistemi ile çalışanlar, sürekli olarak gündüz, sürekli olarak öğleden sonra başlayan ve gece yarısı sona eren veya sürekli olarak gece çalışma söz konusudur. Aksi bir durum olmadıkça, çalışanlar kendi vardiyalarında çalışmak zorundadır. Ancak sosyal hukuk kavramının iş hukukunda daha da belirginleşmesi sonucunda günümüzde uygulaması azalmıştır (Korkusuz, 2005: 3).

Dönüşümlü vardiya sistemi ile çalışanlar, belli bir zaman dilimi içinde dönüşümlü olarak sabah, akşam ve gece çalışmaktadırlar. Dönüşümlü vardiya sistemi kendi içerisinde sürekli vardiyalı çalışma sistemi, yarı sürekli çalışma sistemi ve süreksiz vardiyalı çalışma sistemi olarak 3 gruba ayrılmaktadır (Demirbilek, 2004: 79).

Sürekli vardiyalı çalışma sisteminde işletmeler 7 gün 24 saat ve bayram tatilleri de dâhil olmak üzere kesintisiz bir şekilde çalışmalarına devam etmektedirler. Sürekli vardiyalı çalışma sistemi, üretim kapasitesinden en üst düzeyde yararlanma şansı tanıyan, üretim kaynaklarını optimal bir şekilde kullanmayı sağlayan ve işletmeye geniş açılımlar sağlayan bir çalışma sistemidir (İncir, 1998: 26). Yarı sürekli vardiyalı çalışma sisteminde işletmeler günde 24 saat faaliyetlerine devam ederken hafta sonlarında ve bayramlarda faaliyet göstermemektedirler. Bu çalışma sisteminde 3 ekip veya 3 vardiya söz konusudur. Ekipler sabit veya dönüşümlü olarak sabah, akşam ve gece vardiyalarında çalışmaktadırlar (İncir, 1998: 26). Süreksiz vardiyalı çalışma sisteminde ise işletmeler 24 saat boyunca faaliyetlerini sürdürmektedir. İki ekipli veya çift vardiyalı çalışma sistemi olarak da bilinmektedir (Yıldız vd., 2012: 11).

Ekonomik, sosyal ve sosyo-politik nedenlerle yaygın bir şekilde kullanılan vardiyalı çalışma sistemi, çalışanlarda fiziksel, psikolojik, ailevi ve toplumsal sorunlara neden olabilmektedir (Barton vd., 1994: 749, Pease ve Raether, 2003: 1, Choobineh vd., 2012: 419). Çalışanların gün boyunca tüm biyolojik fonksiyonların idare eden sirkadiyen ritmin bozulması ile ortaya çıan (Finn, 1981: 32) uyku bozukluğu, yorgunluk, kardiyovasküler bozukluklar, gastrointestinal bozukluklar ve kanser en çok karşılaşılan fiziksel problemledir. Depresyon, anksiyete bozukluğu, bellek ve konsantrasyon bozuklukları, tükenmişlik sendromu gibi nedenler psikolojik problemlere neden olurken (Selvi vd., 2010: 239, Sezgin, 2013: 141), 
boşanmaların artması (Sizane ve Van Rensburg, 2011: 71), aile düzenin bozulması, arkadaşlık ilişkilerin kopması, çeşitli sportif, kültürel, sanatsal, dinsel, sivil toplum gibi etkinliklere katılamaması da ailevi ve toplumsal problemlere neden olmaktadır (İncir, 1998: 86).

\section{LITERATÜR TARAMASI}

Hem kamu hem de özel sektörde faaliyet gösteren çeşitli kurum ve kuruluşlar çalışanların performanslarından optimal bir şekilde yararlanmak amacıyla dengeli ve adaletli bir şekilde vardiyaları planlanması gerekmektedir. Sağlık, güvenlik, hizmet, ulaşım, eğitim gibi sektörlerde çalışanlarının vardiya problemlerinin çözümü için literatürde çeşitli çalışmalar bulunmaktadır.

Çalışanların vardiyalarının planlanması amacıyla gerçekleştirilen çalışmaların büyük çoğunluğunu sağlık sektöründe çalışan hemşirelerin ve doktorların vardiyalarının planlanması oluşturmaktadır. Bailey vd. (1997), hemşire çizelgeleme problemini benzetim tekniği ve genetik algoritma ile çözmüşlerdir. Topaloğlu ve Özkarahan (2004), hemşirelerin tur çizelgeleme problemini çözmek amacıyla hedef programlama modeli geliştirmişlerdir. Azaiez ve Al Sharif (2005), hemşire çizelgeleme problemini 0-1 doğrusal hedef programlama yöntemi ile çözmüşlerdir. Brunner vd. (2009), doktorların vardiyalarının planlanması amacıyla karma tamsayılı programlama modeli geliştirmişlerdir. Sungur (2009), hiyerarşik işgücü çizelgeleme problemini çözmek amacıyla tamsayılı programlama modeli geliştirmiştir. Maenhout ve Vanhoucke (2012), hemşirelerin vardiyalarını dengeli bir şekilde planlamak için karma tamsayılı programlama modeli geliştirmişlerdir. Güler vd. (2013), özel bir üniversitenin tıp fakültesine bağlı anesteziyoloji ve reanimasyon bilim dallarında çalışanların vardiyalarının planlanması amacıyla Analitik Hiyerarşi Süreci (AHP)-hedef programlama modeli oluşturmuşlardır. Leeftink vd. (2019), hastaların randevularının planlanması ve mevcut hastaların tedavilerinin planlanması amaciyla stokastik tamsayılı programlama modeli geliştirmişlerdir. Landsman vd. (2019), hastane personellerinin vardiyalarının programlanması ile hastalara verilen hizmetin iyileştirilerek, dengeli bir iş yükü oluşturmak amacıyla hastane personelinin vardiya problemini tamsayılı programlama modeli ile çözmüşlerdir. Tan vd. (2019), bir üniversite hastanesinin acil bölümünde çalışan doktorlarının vardiyalarının planlanması amacıyla bir model önermişlerdir. Doktorların ve hastanenin isteklerini alarak oluşturdukları modelin ağırlıklarını bulmak için öncelikle AHP yönteminden yararlanmış ve optimal sonuca karışık tamsayılı programlama modeli ile ulaşmışlardır.

Güvenlik alanında faaliyet gösteren polis ve güvenlik güçlerinin vardiyalarının planlanması amacıyla çeşitli çalışmalar yapılmıştır. Todovic vd. (2015), polis memurlarının vardiyalarının planlanması için önerdikleri modeli hedef programlama yaklaşımı ile çözmüşlerdir. Ciritcioğlu vd. (2017), güvenlik görevlilerin vardiyalarının planlanması problemini hedef programlama modeli ile modellemişlerdir. Ang vd. (2019), güvenlik görevlilerin yaşadığ1 problemleri ortadan kaldırmak amacıyla güvenlik görevlilerin isteklerini de dikkate alarak tamsayılı doğrusal programlama modeli geliştirmişlerdir.

Hizmet sektöründe faaliyet gösteren fırın, benzin istasyonu, çağrı merkezi, eczane gibi farklı sektörlerde faaliyet gösteren kurum ya da kuruluşlarda çalışanların vardiyalarının planlanması amacıyla çalışmalar mevcuttur. Al-Yakoob ve Sherali (2007), benzin istasyonu çalışanlarının vardiyalarının planlanması amacıyla 2 aşamalı karma tamsayılı programlama 
modeli geliştirmişlerdir. Bhulai vd. (2008), çağrı merkezinde çalışanların vardiyalarının planlanması amacıyla 2 aşamadan meydana gelen tamsayılı programlama modeli geliştirmişlerdir. Birinci aşamada personel seviyesi belirlenmekte ve ikinci adımda da elde edilen personel seviyeleri kullanılarak vardiyaların planlanması gerçekleştirilmiştir. Kassa ve Tizazu (2013), bir otelde çalışan personellerin haftalık olarak çalışacakları vardiya programını tamsayılı programlama modeli ile çözümlemişlerdir. Kocatürk ve Özpeynirci (2014), İzmir ilinde faaliyet gösteren eczanelerin ulusal tatiller, hafta sonları ve geceleri nöbet tutacakları günleri belirlemek amacıyla bir model geliştirmişlerdir. Geliştirdikleri modeli değişken komşuluk arama algoritması, değişken mahalle ayrışma algoritması ve değişken komşuluk kısıtlı arama algoritmaları ile çözmüşlerdir. Özpeynirci ve Ağlamaz (2016), İzmir'de acil tıp ihtiyaçların karşılanması amacıyla 7 gün 24 saat faaliyet gösteren eczanelerin çalışacakları günleri belirlemek amacıyla çoklu p-medyan problemi ile modelleyerek tabu arama algoritması ile mevcut durumu analiz ederek çeşitli çözüm önerileri getirmişlerdir. Çopur vd. (2016), Kırıkkale ilinde faaliyet gösteren merkez ve çevre olarak adlandırılan eczanelerin nöbet çizelgesinin hazırlanması amacıyla AHP yönteminden yararlanmışlardır.

Ulaşım sektöründe yer alan toplu taşıma araçlarının ve toplu taşıma araçları şoförlerinin vardiyalarının planlanması amacıyla çeşitli çalışmalar yapılmıştır. Wren ve Wren (1995), otobüs sürücülerinin vardiyalarının planlanması amacıyla geliştirdikleri modeli gennetik algoritma ile çözmüşlerdir. Li ve Kwan (2003), toplu taşıma sürücülerinin vardiyalarının planlanması amacıyla geliştirdikleri modeli bulanık genetik algoritma ile çözümlemişlerdir. Chu (2007), havaalanı bagaj hizmetlerinde çalışanların vardiyalarının planlanması amacıyla hedef programlama tekniğini kullanmışlardır. Sadjadi ve Esboei (2012), lojistik sektöründe faaliyet gösteren kamyonların yükleme ve boşaltma merkezindeki çalışanların vardiyalarının planlanması amacıyla hedef programlama modeli önermişlerdir. De Bruecker vd. (2018), uçak bakımı çalışanları için gerekli becerileri kazanması ve böylece daha ucuz işgücü programları oluşturabilmek amacıyla çalışanları becerilerine göre eğitim programlarını optimize etmek amacıyla 3 aşamadan oluşan bir karışık tamsayılı programlama modeli önermişlerdir.

Eğitim sektöründe de hem derslerin ve sınavların hem de eğitim alanında çalışanların dengeli ve adaletli bir şekilde planlanması amacıyla çeşitli çalışmalar mevcuttur. Badri (1996), öğretim elemanlarının ders programlarının planlanması amacıyla çok amaçlı 0-1 tamsayılı programlama modeli geliştirmiştir. İlkuçar (2011), meslek yüksekokullarda sınırla sayıda bulunan öğretim elemanlarının vize ve final gibi sınavlarda gözetmenliklerinin planlanması amacıyla bir model ve yazılım geliştirmiştir. Küçüksille ve Tokmak (2014), yapay arı kolonisi algoritmasını kullanarak bir üniversitede okutulacak olan ders programının çizelgeleme problemini ele almışlardır. Gupta vd. (2018), Portland State Üniversitesi kütüphanesinde çalışan personelin fazla çalışma sürelerini azaltan ve personel tercihlerini dikkate alan bir model geliştirmişlerdir.

İnsanların ve hayvanların güvenliğini tehlikeye sokan durumlardan kurtarmak için faaliyet gösteren itfaiye erlerinin vardiyalarının planlanması amacıyla çeşitli çalışmalar mevcuttur. Fry vd. (2006), Cincinnati İtfaiyesi'nde toplam maliyeti en aza indirmek amaciyla minimum itfaiye eri sayısı, israfın azaltılması ve geçici devamsızlıkları azaltmak amacıyla nicel bir model geliştirmişlerdir. Stevanović vd. (2006), konser, spor turnuvaları, müzik etkinlikleri 
gibi durumlarda gerekli olan en uygun itfaiye eri sayısını belirlemek ve bu itfaiye erlerinin çalışacakları vardiyaları belirlemek amacıyla doğrusal programlama modeli geliştirmişlerdir. Wu vd. (2019), sinırlı kurtarma ekibi kaynaklarına ve öncelikli afet alanlarına sahip olan orman yangınları için acil durumum planlama problemi ele alınmaktadır. Sınırlı sayıda bulunan orman yangınları ile mücadele ekiplerinin toplam mesafesini en aza indirmek ve en kısa sürede yangınları söndürmek amacıyla tamsayılı doğrusal programlama modelini ele almışlardır.

Bu çalışmada, insanların ve hayvanların güvenliğini tehlikeye sokan durumlarda, onların can ve mal güvenliğinin sağlanmasında sorumlu olan itfaiye erlerinin çalışacakları vardiyaların planlanması problemi ele alınmıştır. Literatürde az sayıda çalışma bulunan itfaiye erlerinin vardiyalarının çizelgelenmesini ele alan bu çalışma, manuel şekilde hazırlanan çizelgelere göre çok kısa bir sürede hazırlanması yanında itfaiye erleri ve itfaiye istasyonunun isteklerini dikkate alması dolayısıyla diğer çalışmalardan ayrılmaktadır.

\section{TAMSAYILI PROGRAMLAMA}

Tamsayılı programlama, doğrusal programlama problemlerine optimum tamsayı çözümü türetmek için geliştirilen doğrusal programlamanın özel bir uzantısıdır. Değişkenlerin bir kısmının veya tamamının tamsayılı değerler aldığı, genel doğrusal programlama modelinden elde edilen optimizasyon problemlerin bir sınıfıdır (Ergülen vd., 2005: 165). Tamsayılı programlama modelinde, gerçek hayatta birçok problemin sonucunun tamsayılı değerler alması nedeniyle değişkenlerin tamsayılı değerler almaktadır (Sierksma, 2002: 209).

Tamsayılı programlama ile ilgili çalışmalar, 1950'li yıllarda Gomory, Land ve Doing tarafından çeşitli alanlarda yapılan çalışmalara dayanmaktadır (Milano, 2004: 15). Daha sonraki yıllarda yöntem, geniş bir uygulama alanı bulmuştur. Günümüzde, montaj hattının dengelenmesi, atama problemi, personel çizelgeleme, yer seçimi, reklamların çizelgelenmesi, üretim planlanması, araç rotalama gibi birçok problemin çözümünde kullanılmaktadır.

Tamsayılı programlama modeli, doğrusal programlama modelinde meydana gelebilecek olan ve gerçeği yansıtmayan sonuçları ortadan kaldırmayı amaçlamaktadır. Bazı doğrusal programlama modellerinde sonuçların tamsayı çıkmaması, modelin gerçek hayattaki problemlere uygunluğunu bozmaktadır (Akay, 2009: 17). Örneğin bir iş yerine çeşitli makine ve teçhizatın alınması, bir makinaya işçinin atanması, ek bir binanın kurulacağı yerin belirlenmesi, üretilecek olan ürünlerin sayısı gibi.

Genel olarak tamsayılı programlama modeli Eşitlik (1), (2) ve (3)'te gösterilmiştir (Tütek ve Gümüşoğlu, 2008: 260):

$Z_{\max / \min }=\sum_{j=1}^{n} c_{j} x_{j}$

Kisitlayıcılar,

$\sum_{j=1}^{n} a_{i j} x_{j}(=, \leq, \geq) b_{i} \quad(i=1,2, \ldots, n)$

$x_{j} \geq 0$ ve tamsayı 
Değişkenler;

$c_{j=}$ Kar ve maliyet değişkeni

$x_{j=}$ Karar değişkeni

$b_{i=}$ Sinırlayıcı şart

$a_{i j=}$ Girdi miktarı

Tamsayılı programlama probleminin çözümü için oluşturulan modelde karar değişkenlerinin alacakları tamsayılı değerlere göre saf tamsayılı programlama, karma tamsayılı programlama ve 0-1 tamsayılı programlama olmak üzere 3 tipte görülebilmektedir (Muğaoğlu, 1987: 17).

Saf Tamsayılı Programlama; tamsayılı programlama modelinde yer alan tüm değişkenlerin tümünün tamsayılı değerler alması söz konusu ise saf (arı, bütünüyle) tamsayılı programlama olarak adlandırılır ve personel programlama problemleri saf tamsayılı programlama problemlerindendir (Şengül, 2010: 121). Genel olarak saf tamsayılı programlama modeli Eşitlik (4), (5) ve (6)'da gösterilmiştir.

$Z_{\max / \min }=\sum_{j=1}^{n} c_{j} x_{j}$

$\sum_{j=1}^{n} a_{i j} x_{j}(=, \leq, \geq) b_{i} \quad(i=1,2, \ldots, n)$

$x_{j} \geq 0$ ve tamsayı

Karma Tamsayılı Programlama; tamsayılı programlama modelinde, bazı değişkenlerin tamsayı değerli olması gerekli iken diğer değişkenler bölünebilirlik varsayımını karşılayan yani kesirli değerler alabilen değişkenler ise bu türden problemler karma tamsayılı programlama olarak adlandırılır (Öztürk, 2005: 335). Karma tamsayılı programlama algoritmalarının en önemli özelliği uygun çözümlere kolayca ulaşılabilir olmasıdır. Bu amaçla karma tamsayılı programlama yaygın bir şekilde kullanılmaktadır (Andrade, 2017: 62). Genel olarak karma tamsayılı programlama modeli Eşitlik (7), (8) ve (9)'da gösterilmiştir.

$Z_{\max / \min }=\sum_{j=1}^{n} c_{j} x_{j}$

$\sum_{j=1}^{n} a_{i j} x_{j}(=, \leq, \geq) b_{i} \quad(i=1,2, \ldots, n)$

$x_{j} \geq 0 \exists i$ için $x_{j}$ tamsayı

0- 1 Tamsayılı Programlama; tamsayılı programalam modelinde bulunan tüm değişkenlerin 0 ya da 1'e eşit olmasının istendiği modellere 0-1 tamsayılı programlama problemi denilmektedir (Gürbüz ve Cömert, 2015: 105). Çeşitli ürünler üreten bir fabrika da mevcut olan ürünlerden hangilerinin üretilip üretilmeyeceği, yeni bir tesis kurmak isteyen fabrikanın bu tesisi kuracağı yerin seçimi, bir fabrika da çalışan işçilerin mevcut makinelerin hangisinde çalışıp çalışmayacağının belirlenmesi vb. durumlarda 0-1 tamsayılı programlama 
tekniğinden yararlanılır. Genel olarak karma tamsayılı programlama modeli Eşitlik (10), (11) ve (12)'de gösterilmiştir.

$Z_{\max / \min }=\sum_{j=1}^{n} c_{j} x_{j}$

$\sum_{j=1}^{n} a_{i j} x_{j}(=, \leq, \geq) b_{i} \quad(i=1,2, \ldots, n)$

$x_{j}= \begin{cases}0 \text { ya da } 1\} \\ \text { S }\end{cases}$

\section{UYGULAMA}

$\mathrm{Bu}$ çalışmada; yangın, deprem, sel, patlama, çökme, arama, kurtarma gibi insanların ve hayvanların güvenliğini tehlikeye sokan durumlarda, onların can ve mal güvenliğinin sağlanmasında sorumlu olan itfaiye erlerinin çalışacakları vardiyaların planlanması problemi ele alınmıştır. Ele alınan problem, Denizli'de kırk iki itfaiye erinin çalıştığı bir itfaiye istasyonunda çalışan itfaiye erlerini kapsamaktadır. Optimal bir çalışma düzeninin oluşturulması için itfaiye erlerinin tüm vardiyalara dengeli ve adaletli bir şekilde atanması amacıyla idarenin ve itfaiye erlerinin istekleri doğrultusunda bir model oluşturmuştur.

İtfaiye erlerinin vardiyalarının planlanması amacıyla idarenin ve itfaiye erlerinin istekleri doğrultusunda hazırlanan modelde bazı varsayımlar yapılmıştır. Bu varsayımlar şu şekildedir (Yelek vd., 2019: 22):

- İtfaiye erlerinin vardiyalarının planlanma dönemi bir aylık süreyi kapsayan 30 gün için yapılmıştır.

- Resmi bayramları ve dini bayramları kapsayan tatil günleri modelde dikkate alınmamıştır.

- İtfaiye erlerinin yıllık izinleri dikkate alınmamıştır.

- Vardiya planının ilk günü haftanın herhangi bir gününü göstermektedir.

İtfaiye idaresi ve itfaiye erlerinin istekleri yanında varsayımlar da dikkate alınarak oluşturulan model, Inter ${ }^{\circledR}$ Core TM İ7- 4790 CPU @ 3.60 GHz işlemcisine sahip 8 GB belleği olan Windows 10 işletim sistemi olan bir bilgisayarda matematiksel programlama ve optimizasyon programlama problemlerin çözümünde kullanılan GAMS 23.5 paket programında modellenmiş ve CPLEX çözücüsü kullanılarak, çözüme ulaşılmıştır

\section{Çalışma Prensipleri:}

21.10.2016 tarihli 26326 sayılı Resmî Gazetede yayımlanan "Belediye İtfaiye Yönetmeliği" gereğince 14.07.1965 tarihli 657 sayılı Devlet Memurları Kanunu'nda ifade edilen çalışma sürelerine bağlı kalınmaksızın tatil günlerini de kapsayacak şekilde itfaiye erleri için bir çalışma sistemi oluşturulması maddesini dikkate alarak, ilgili istasyon şefi ile yapılan görüşmeler sonucunda çeşitli prensipler ele alınmıştır.

\section{İtfaiye İstasyonunun Belirlediği Kurallar:}

- Uygulama yapılan istasyonda A, B ve C adı verilen 3 tip vardiya vardır. Bu vardiya sistemi, itfaiye erleri 24 saatlik çalışma sürelerini dönüşümlü olarak ifa ettikleri çalışma programıdır. Bu çalışma programında ilk gün vardiyası olan A tipi vardiya 
sistemi 8.30-.8-30 saatleri arasındaki çalışma süresini kapsamaktadır. İkinci gün vardiyası olan B tipi vardiya sistemi 8.30-8.30 saatleri arasındaki çalışma sürelerini ve üçüncü gün vardiyası olan C tipi vardiya sistemi de 8.30-8.30 saatleri arasındaki çalışma süresini kapsamaktadır.

- Vardiyalarda gerekli olan itfaiye eri sayısı karşılanması gerekmektedir.

- İtfaiye erleri vardiyaların sadece bir tanesinde çalışması gerekmektedir.

- 24 saat çalışan bir itfaiye eri izleyen iki gün (48 saat) dinlenmelidir.

- İstasyonda, 42 itfaiye eri, 1 itfaiye şefi ve 1 aşçı çalışmaktadır (İtfaiye şefi ve aşçı vardiyalı çalışma sistemi ile çalışmadığı için çalışmaya dâhil edilmemiştir).

- İtfaiye erlerinin aylık en fazla çalışabilecekleri çalışma süresi toplam 240 saattir.

- Bir itfaiye eri ayda en fazla 10 kez vardiyalı bir şekilde çalışmalıdır.

- İstasyonda, bir vardiyada minimum 14 itfaiye eri çalışmalıdır.

\section{İtfaiye Erlerinin Özel İstekleri:}

- 3, 18 ve 40 numaralı itfaiye erleri farklı vardiyalarda çalışmak istemektedirler.

- $1,8,17$ ve 20 numaralı itfaiye erleri aynı vardiyada çalışmak istemektedir.

- 29 numaralı itfaiye eri 12. gün çalışmak istememektedir.

- 13 numaralı itfaiye eri 14. gün çalışmak istememektedir.

\section{Karar Değişkenleri:}

Matematiksel modelde kullanilan indisler:

$\mathrm{i}=1,2, \ldots, \mathrm{n}$ toplam itfaiye eri

$\mathrm{j}=1,2, \ldots, \mathrm{m}$ gün sayısı

$k=1, \ldots, \quad p$ vardiya sayıs 1

$\mathrm{v}=$ vardiya çalışma süresi

$\mathrm{X}_{\mathrm{ijk}}=\mathrm{i}$. itfaiye erinin, ayın $\mathrm{j}$. günü $\mathrm{k}$. vardiyasında çalışıyorsa 1 , aksi durumda 0

$\mathrm{y}_{\mathrm{ij}}=\mathrm{i}$. itfaiye erinin, ayın $\mathrm{j}$. günü vardiyada çalışıyorsa 0 , aksi durumda 1

\section{Kisitlar:}

$\min Z=\sum_{k=1}^{p} \sum_{j=1}^{m} \sum_{i=1}^{n} x_{i j k}$

$x_{i j k}=1-y_{i j}$

$\sum_{k=1}^{p} x_{i(j+1) k}+x_{i(j+2) k} \leq y_{i j}$

$\sum_{i=1}^{n} x_{i j k} \geq 14$ 


$$
\begin{aligned}
& \sum_{k=1}^{p} x_{i j k} \leq 1 \\
& \sum_{k=1}^{p} \sum_{j=1}^{m} x_{i j k} \leq 10 \\
& \sum_{k=1}^{p} \sum_{j=1}^{m} x_{i j k} v v \leq 240 \\
& x_{3 j k}+x_{18 j k}+x_{40 j k} \geq 1 \\
& x_{1 j k}=1 \\
& x_{8 j k}=1 \\
& x_{17 j k}=1 \\
& x_{20 j k}=1 \\
& x_{29(12) k}=0 \\
& x_{13(14) k}=0 \\
& x_{i j k} \in\{0,1\}
\end{aligned}
$$

İtfaiye erlerinin 1 aylık vardiyalarının planlanması amacıyla oluşturulan model Eşitlik (13)(27)'de gösterilmiştir. Eşitlik (13)'te istasyonda, vardiyalara atanan itfaiye erlerinin sayısını küçüklenmesini, Eşitlik (14)-(15)' te bir itfaiye erinin 24 saatlik vardiyada çalışma ve vardiya sonrasında 48 saat dinlenmesini, Eşitlik (16) söz konusu vardiyalarda minimum 14 kişinin çalışabileceğini, Eşitlik (17) itfaiye erlerinin vardiyalara $1 \mathrm{kez}$ atanacağını, Eşitlik (18) itfaiye erlerinin aylık en fazla $10 \mathrm{kez} 24$ saatlik vardiyaya atanacağını, Eşitlik (19) bir itfaiye erinin bir ay içerisinde çalışabileceği maksimum süreyi, Eşitlik (20) 3, 18 ve 40 numaralı itfaiye erlerinin farklı vardiyalarda çalışacağını, Eşitlik (21)-(24) 1, 8, 17 ve 20 numaralı itfaiye erlerinin aynı vardiyada çalışacağını, Eşitlik (25) 29 numaralı itfaiye erinin 14 . gün çalışmak istememesini, Eşitlik (26) 13 numaralı itfaiye erinin 14. gün çalışmak istememesini ve Eşitlik (27) değişkenlerin tamsayılı değerler alacağını ifade etmektedir.

İtfaiye istasyonun çalışma saatleri ve itfaiye erlerinin çalışacakları vardiyaların belirlenmesinde tamsayılı programlama yöntemi ile model Eşitlik (13)-(29)'da gösterilmiştir. Oluşturulan bu matematiksel model, GAMS 23.5 paket programı yardımıyla çözülmüş ve itfaiye erlerinin 30 günlük vardiya programı Tablo (1)'de gösterilmiştir. 
Tablo 1: İtfaiye Erlerinin Vardiya Planları

\begin{tabular}{|c|c|c|c|c|c|c|c|c|c|c|c|c|c|c|c|c|c|c|c|c|c|c|c|c|c|c|c|c|c|c|c|}
\hline $\mathrm{a}$ & b & 1 & 2 & 3 & 4 & 5 & 6 & 7 & 8 & 9 & 10 & 11 & 12 & 13 & 14 & 15 & 16 & 17 & 18 & 19 & 20 & 21 & 22 & 23 & 24 & 25 & 26 & 27 & 28 & 29 & 30 \\
\hline 1 & 1 & 1 & 0 & 0 & 1 & 0 & 0 & 1 & 0 & 0 & 1 & 0 & 0 & 1 & 0 & 0 & 1 & 0 & 0 & 1 & 0 & 0 & 1 & 0 & 0 & 1 & 0 & 0 & 1 & 0 & 0 \\
\hline 8 & 2 & 1 & 0 & 0 & 1 & 0 & 0 & 1 & 0 & 0 & 1 & 0 & 0 & 1 & 0 & 0 & 1 & 0 & 0 & 1 & 0 & 0 & 1 & 0 & 0 & 1 & 0 & 0 & 1 & 0 & 0 \\
\hline 15 & 3 & 1 & 0 & 0 & 1 & 0 & 0 & 1 & 0 & 0 & 1 & 0 & 0 & 1 & 0 & 0 & 1 & 0 & 0 & 1 & 0 & 0 & 1 & 0 & 0 & 1 & 0 & 0 & 1 & 0 & 0 \\
\hline 17 & 4 & 1 & 0 & 0 & 1 & 0 & 0 & 1 & 0 & 0 & 1 & 0 & 0 & 1 & 0 & 0 & 1 & 0 & 0 & 1 & 0 & 0 & 1 & 0 & 0 & 1 & 0 & 0 & 1 & 0 & 0 \\
\hline 18 & 5 & 1 & 0 & 0 & 1 & 0 & 0 & 1 & 0 & 0 & 1 & 0 & 0 & 1 & 0 & 0 & 1 & 0 & 0 & 1 & 0 & 0 & 1 & 0 & 0 & 1 & 0 & 0 & 1 & 0 & 0 \\
\hline 19 & 6 & 1 & 0 & 0 & 1 & 0 & 0 & 1 & 0 & 0 & 1 & 0 & 0 & 1 & 0 & 0 & 1 & 0 & 0 & 1 & 0 & 0 & 1 & 0 & 0 & 1 & 0 & 0 & 1 & 0 & 0 \\
\hline 20 & 7 & 1 & 0 & 0 & 1 & 0 & 0 & 1 & 0 & 0 & 1 & 0 & 0 & 1 & 0 & 0 & 1 & 0 & 0 & 1 & 0 & 0 & 1 & 0 & 0 & 1 & 0 & 0 & 1 & 0 & 0 \\
\hline 22 & 8 & 1 & 0 & 0 & 1 & 0 & 0 & 1 & 0 & 0 & 1 & 0 & 0 & 1 & 0 & 0 & 1 & 0 & 0 & 1 & 0 & 0 & 1 & 0 & 0 & 1 & 0 & 0 & 1 & 0 & 0 \\
\hline 30 & 9 & 1 & 0 & 0 & 1 & 0 & 0 & 1 & 0 & 0 & 1 & 0 & 0 & 1 & 0 & 0 & 1 & 0 & 0 & 1 & 0 & 0 & 1 & 0 & 0 & 1 & 0 & 0 & 1 & 0 & $\underline{U}$ \\
\hline 31 & 10 & 1 & 0 & 0 & 1 & 0 & 0 & 1 & 0 & 0 & 1 & 0 & 0 & 1 & 0 & 0 & 1 & 0 & 0 & 1 & 0 & 0 & 1 & 0 & 0 & 1 & 0 & 0 & 1 & 0 & 0 \\
\hline 34 & 11 & 1 & 0 & 0 & 1 & 0 & 0 & 1 & 0 & 0 & 1 & 0 & 0 & 1 & 0 & 0 & 1 & 0 & 0 & 1 & 0 & 0 & 1 & 0 & 0 & 1 & 0 & 0 & 1 & 0 & 0 \\
\hline 36 & 12 & 1 & 0 & 0 & 1 & 0 & 0 & 1 & 0 & 0 & 1 & 0 & 0 & 1 & 0 & 0 & 1 & 0 & 0 & 1 & 0 & 0 & 1 & 0 & 0 & 1 & 0 & 0 & 1 & 0 & 0 \\
\hline 37 & 13 & 1 & 0 & 0 & 1 & 0 & 0 & 1 & 0 & 0 & 1 & 0 & 0 & 1 & 0 & 0 & 1 & 0 & 0 & 1 & 0 & 0 & 1 & 0 & 0 & 1 & 0 & 0 & 1 & 0 & 0 \\
\hline 41 & 14 & 1 & 0 & 0 & 1 & 0 & 0 & 1 & 0 & 0 & 1 & 0 & 0 & 1 & 0 & 0 & 1 & 0 & 0 & 1 & 0 & 0 & 1 & 0 & 0 & 1 & 0 & 0 & 1 & 0 & 0 \\
\hline 2 & 15 & 0 & 1 & 0 & 0 & 1 & 0 & 0 & 1 & 0 & 0 & 1 & 0 & 0 & 1 & 0 & 0 & 1 & 0 & 0 & 1 & 0 & 0 & 1 & 0 & 0 & 1 & 0 & 0 & 1 & 0 \\
\hline 3 & 16 & 0 & 1 & 0 & 0 & 1 & 0 & 0 & 1 & 0 & 0 & 1 & 0 & 0 & 1 & 0 & 0 & 1 & 0 & 0 & 1 & 0 & 0 & 1 & 0 & 0 & 1 & 0 & 0 & 1 & 0 \\
\hline 4 & 17 & 0 & 1 & 0 & 0 & 1 & 0 & 0 & 1 & 0 & 0 & 1 & 0 & 0 & 1 & 0 & 0 & 1 & 0 & 0 & 1 & 0 & 0 & 1 & 0 & 0 & 1 & 0 & 0 & 1 & 0 \\
\hline 5 & 18 & 0 & 1 & 0 & 0 & 1 & 0 & 0 & 1 & 0 & 0 & 1 & 0 & 0 & 1 & 0 & 0 & 1 & 0 & 0 & 1 & 0 & 0 & 1 & 0 & 0 & 1 & 0 & 0 & 1 & 0 \\
\hline 6 & 19 & 0 & 1 & 0 & 0 & 1 & 0 & 0 & 1 & 0 & 0 & 1 & 0 & 0 & 1 & 0 & 0 & 1 & 0 & 0 & 1 & 0 & 0 & 1 & 0 & 0 & 1 & 0 & 0 & 1 & 0 \\
\hline 12 & 20 & 0 & 1 & 0 & 0 & 1 & 0 & 0 & 1 & 0 & 0 & 1 & 0 & 0 & 1 & 0 & 0 & 1 & 0 & 0 & 1 & 0 & 0 & 1 & 0 & 0 & 1 & 0 & 0 & 1 & 0 \\
\hline 16 & 21 & 0 & 1 & 0 & 0 & 1 & 0 & 0 & 1 & 0 & 0 & 1 & 0 & 0 & 1 & 0 & 0 & 1 & 0 & 0 & 1 & 0 & 0 & 1 & 0 & 0 & 1 & u & 0 & 1 & U \\
\hline 23 & 22 & 0 & 1 & 0 & 0 & 1 & 0 & 0 & 1 & 0 & 0 & 1 & 0 & 0 & 1 & 0 & 0 & 1 & 0 & 0 & 1 & 0 & 0 & 1 & 0 & 0 & 1 & 0 & 0 & 1 & 0 \\
\hline 26 & 23 & 0 & 1 & 0 & 0 & 1 & 0 & 0 & 1 & 0 & 0 & 1 & 0 & 0 & 1 & 0 & 0 & 1 & 0 & 0 & 1 & 0 & 0 & 1 & 0 & 0 & 1 & 0 & 0 & 1 & 0 \\
\hline 29 & 24 & 0 & 1 & 0 & 0 & 1 & 0 & 0 & 1 & 0 & 0 & 1 & 0 & 0 & 1 & 0 & 0 & 1 & 0 & 0 & 1 & 0 & 0 & 1 & 0 & 0 & 1 & 0 & 0 & 1 & 0 \\
\hline
\end{tabular}




\begin{tabular}{|c|c|c|c|c|c|c|c|c|c|c|c|c|c|c|c|c|c|c|c|c|c|c|c|c|c|c|c|c|c|c|c|}
\hline 32 & 25 & 0 & 1 & 0 & 0 & 1 & 0 & 0 & 1 & 0 & 0 & 1 & 0 & 0 & 1 & 0 & 0 & 1 & 0 & 0 & 1 & 0 & 0 & 1 & 0 & 0 & 1 & 0 & 0 & 1 & 0 \\
\hline 33 & 26 & 0 & 1 & 0 & 0 & 1 & 0 & 0 & 1 & 0 & 0 & 1 & 0 & 0 & 1 & 0 & 0 & 1 & 0 & 0 & 1 & 0 & 0 & 1 & 0 & 0 & 1 & 0 & 0 & 1 & 0 \\
\hline 35 & 27 & 0 & 1 & 0 & 0 & 1 & 0 & 0 & 1 & 0 & 0 & 1 & 0 & 0 & 1 & 0 & 0 & 1 & 0 & 0 & 1 & 0 & 0 & 1 & 0 & 0 & 1 & 0 & 0 & 1 & 0 \\
\hline 38 & 28 & 0 & 1 & 0 & 0 & 1 & 0 & 0 & 1 & 0 & 0 & 1 & 0 & 0 & 1 & 0 & 0 & 1 & 0 & 0 & 1 & 0 & 0 & 1 & 0 & 0 & 1 & 0 & 0 & 1 & 0 \\
\hline 7 & 29 & 0 & 0 & 1 & 0 & 0 & 1 & 0 & 0 & 1 & 0 & 0 & 1 & 0 & 0 & 1 & 0 & 0 & 1 & 0 & 0 & 1 & 0 & 0 & 1 & 0 & 0 & 1 & 0 & 0 & 1 \\
\hline 9 & 30 & 0 & 0 & 1 & 0 & 0 & 1 & 0 & 0 & 1 & 0 & 0 & 1 & 0 & 0 & 1 & 0 & 0 & 1 & 0 & 0 & 1 & 0 & 0 & 1 & 0 & 0 & 1 & 0 & 0 & 1 \\
\hline 10 & 31 & 0 & 0 & 1 & 0 & 0 & 1 & 0 & 0 & 1 & 0 & 0 & 1 & 0 & 0 & 1 & 0 & 0 & 1 & 0 & 0 & 1 & 0 & 0 & 1 & 0 & 0 & 1 & 0 & 0 & 1 \\
\hline 11 & 32 & 0 & 0 & 1 & 0 & 0 & 1 & 0 & 0 & 1 & 0 & 0 & 1 & 0 & 0 & 1 & 0 & 0 & 1 & 0 & 0 & 1 & 0 & 0 & 1 & 0 & 0 & 1 & 0 & 0 & 1 \\
\hline 13 & 33 & 0 & 0 & 1 & 0 & 0 & 1 & 0 & 0 & 1 & 0 & 0 & 1 & 0 & 0 & 1 & 0 & 0 & 1 & 0 & 0 & 1 & 0 & 0 & 1 & 0 & 0 & 1 & 0 & 0 & 1 \\
\hline 14 & 34 & 0 & 0 & 1 & 0 & 0 & 1 & 0 & 0 & 1 & 0 & 0 & 1 & 0 & 0 & 1 & 0 & 0 & 1 & 0 & 0 & 1 & 0 & 0 & 1 & 0 & 0 & 1 & 0 & 0 & 1 \\
\hline 21 & 35 & 0 & 0 & 1 & 0 & 0 & 1 & 0 & 0 & 1 & 0 & 0 & 1 & 0 & 0 & 1 & 0 & 0 & 1 & 0 & 0 & 1 & 0 & 0 & 1 & 0 & 0 & 1 & 0 & 0 & 1 \\
\hline 24 & 36 & 0 & 0 & 1 & 0 & 0 & 1 & 0 & 0 & 1 & 0 & 0 & 1 & 0 & 0 & 1 & 0 & 0 & 1 & 0 & 0 & 1 & 0 & 0 & 1 & 0 & 0 & 1 & 0 & 0 & 1 \\
\hline 25 & 37 & 0 & 0 & 1 & 0 & 0 & 1 & 0 & 0 & 1 & 0 & 0 & 1 & 0 & 0 & 1 & 0 & 0 & 1 & 0 & 0 & 1 & 0 & 0 & 1 & 0 & 0 & 1 & 0 & 0 & 1 \\
\hline 27 & 38 & 0 & 0 & 1 & 0 & 0 & 1 & 0 & 0 & 1 & 0 & 0 & 1 & 0 & 0 & 1 & 0 & 0 & 1 & 0 & 0 & 1 & 0 & 0 & 1 & 0 & 0 & 1 & 0 & 0 & 1 \\
\hline 28 & 39 & 0 & 0 & 1 & 0 & 0 & 1 & 0 & 0 & 1 & 0 & 0 & 1 & 0 & 0 & 1 & 0 & 0 & 1 & 0 & 0 & 1 & 0 & 0 & 1 & 0 & 0 & 1 & 0 & 0 & 1 \\
\hline 39 & 40 & 0 & 0 & 1 & 0 & 0 & 1 & 0 & 0 & 1 & 0 & 0 & 1 & 0 & 0 & 1 & 0 & 0 & 1 & 0 & 0 & 1 & 0 & 0 & 1 & 0 & 0 & 1 & 0 & 0 & 1 \\
\hline 40 & 41 & 0 & 0 & 1 & 0 & 0 & 1 & 0 & 0 & 1 & 0 & 0 & 1 & 0 & 0 & 1 & 0 & 0 & 1 & 0 & 0 & 1 & 0 & 0 & 1 & 0 & 0 & 1 & 0 & 0 & 1 \\
\hline 42 & 42 & 0 & 0 & 1 & 0 & 0 & 1 & 0 & 0 & 1 & 0 & 0 & 1 & 0 & 0 & 1 & 0 & 0 & 1 & 0 & 0 & 1 & 0 & 0 & 1 & 0 & 0 & 1 & 0 & 0 & 1 \\
\hline
\end{tabular}


İtfaiye erlerinin aylık çalışması gereken vardiyalar dengeli bir şekilde oluşturulmuş ve bu vardiyalar Tablo (1)'de gösterilmiştir. Tablo (1)'de yer alan itfaiye erlerinin çalışacakları vardiyaları gösteren vardiyalar Tablo (2)'de genel olarak özetlenmiştir.

Tablo 2. İtfaiye Erlerinin Vardiya Programının Genel Görünümü

\begin{tabular}{|c|c|c|}
\hline Vardiyalar & Itfaiye Erleri & Günler \\
\hline \multirow{2}{*}{ A } & $\begin{array}{c}1,8,15,17,18,19,20,22,30,31, \\
34,36,37 \text { ve 41 }\end{array}$ & $\begin{array}{c}1,4,7,10,13,16 \\
19,22,25 \text { ve 28 }\end{array}$ \\
\hline \multirow{2}{*}{ B } & $\begin{array}{c}2,3,4,5,6,12,16,23,26,19,32, \\
\text { 33, 35 ve 38 }\end{array}$ & $\begin{array}{c}2,11,14, \\
17,20,23,26 \text { ve 29 }\end{array}$ \\
\hline \multirow{2}{*}{ C } & $7,9,10,11,13,21,24,25,27,28$, \\
39,40 ve 42 & $\begin{array}{c}3,6,9,12,15, \\
18,21,24,27 \text { ve } 30\end{array}$ \\
\hline
\end{tabular}

Hazırlanan bu çizelgeleme ile, yangın, deprem, sel, patlama, çökme, arama, kurtarma gibi insanların ve hayvanların güvenliğini tehlikeye sokan durumlarda, onların can ve mal güvenliğinin sağlanmasında sorumlu olan itfaiye erlerinin verimliliklerinin arttırılması amacıyla vardiya planlaması hazırlanmıştır. Ayrıca itfaiye erlerinin, fiziksel ve zihinsel olarak yorgunluk seviyelerinin azaltılması amaçlanmıştır.

\section{SONUÇ VE ÖNERILER}

Bu çalışmada, yangın, deprem, sel, patlama, çökme, arama, kurtarma gibi meydana gelen olumsuz olaylarda insanların ve hayvanların güvenliğini tehlikeye sokan durumlardan kurtarmak amacıyla 7 gün 24 saat boyunca çalışan itfaiye erleri için aylık çalışma planı oluşturulması amaçlanmıştır. İtfaiye erlerinin çalışmasını düzenleyen ilgili kanunlar, itfaiye idaresinin ve itfaiye erleri ile yapılan görüşmeler sonrasında elde edilen veriler tamsayılı programlama ile modellenmiş ve GAMS paket programı ile çözümlenen model ile optimal çalışma planı oluşturulmuştur. Oluşturulan çalışma planı kırk iki itfaiye eri için otuz günlük bir çalışma planını kapsamında hazırlanmış ve itfaiye istasyon şefinin manuel olarak hazırladığı çalışma planı ile karşılaştırılmıştır. Oluşturulan çizelge ile manuel çizelgeler karşılaştırıldığında itfaiye erlerinin isteklerinin karşılanması ile verimliliklerinin ve memnuniyetlerinin artması, ardışık olarak yoğun çalışma temposunun azaltılmasına bağlı olarak fiziksel ve psikolojik iyileşmeler yaşanması öngörülmüştür.

Gelecekte itfaiye erlerinin vardiyalarının planlanması amacıyla çalışma yapacak olan araştırmacılara; çalışmaya farklı kısıtlar ekleyerek, farklı matematiksel programlama teknikleri, simülasyon ve sezgisel algoritmalar vb. kullanılarak sonuçların karşılaştırılması önerilebilir. Ayrıca, çalışanların resmi bayramlar ya da dini bayramlardaki izinleri, yaz tatili, yıllık izin veya kendilerinin ya da ailelerinin hastalıkları durumunda vardiyalarda değişikliği dikkate alan esnek vardiya sistemleri ele alınarak çalışma genişletilebilir.

\section{KAYNAKÇA}

Akay, D. (2009). Filo Ataması Problemi ve Karmaşık Tam Sayı Programlama ile En İyileme Yöntemleri, (Basılmamış Yüksek Lisans Tezi), İstanbul Teknik Üniversitesi Fen Bilimleri Enstitüsü, İstanbul.

Akyol Güner, T. (2010). Çalışma Yaşamında Vardiya Çalışması ve Uyku ile İlgili Özelliklerin Değerlendirilmesi, (Basılmamış Yüksek Lisans Tezi), Zonguldak Karaelmas Üniversitesi Sağlık Bilimleri Enstitüsü, Zonguldak. 
Al-Yakoob, S. M. \& Sherali, H. D. (2007). Mixed-integer programming models for an employee scheduling problem with multiple shifts and work locations. Annals of Operations Research, 155/1, 119- 142.

Andrade, C. E., Ahmed, S, Nemhauser, G. L. \& Shao, Y. (2017). A hybrid primal heuristic for finding feasible solutions to mixed integer programs. Europan Journal of Operational Research, 263/1, 62- 71 .

Ang, S. Y., Razali, M., Asyikin, S. N. \& Kek, S. L. (2019). Optimized preference of security staff scheduling using integer linear programming approach. An International Journal of Advanced Computer Technology, 8(4), 3103- 3111.

Arpacı, F. (2007). Vardiya Usulü Çalışmanın Hemşirelerin Sosyal Yaşamı ve Ev Yaşamı Üzerindeki Etkilerinin İncelenmesi, NWSA: Life Sciences, 2/4, 71- 79.

Azaiez, M. N. \& Al Sharif, S. S. (2005). A 0-1 goal programming model for nurse scheduling. Computers \& Operations Research, 32/3, 491- 507.

Badri, M. A. (1996). A two-stage multiobjective scheduling model for [faculty-course-time] assignments. European Journal of Operational Research, 94(1), 16-28.

Bailey, R. N., Garner, K. M. \& Hobbs, M. F. (1997). Using simulated annealing and genetic algorithms to solve staff-scheduling problems. Asia-Pacific Journal of Operational Research, 14/2.

Bambra, C. L., Whitehead, M. M., Sowden, A. J., Akers, J. \& Petticrew, M. P. (2008). Shifting schedules: The healt effects of reorganizing shift work. American Journal of Preventive Medicine, 34/5, 427- 434.

Barton, J., Folkard, S., Smith, L. \& Poole, C. (1994). Effects on health of a change from a delaying to an advancing shift system. Occupational and Environmental Medicine, 51/11, 749- 755 .

Bhulai, S., Koole, G. \& Pot, A. (2008). Simple methods for shift scheduling in multiskill call centers. Manufacturing \& Service Operations Management, 10/3 411-420.

Brunner, J. O., Bard, J. F. \& Kolisch, R. (2009). Flexible shift scheduling of physicians. Health Care Management Science, 12/3, 285- 305.

Choobineh, A., Soltanzadeh, A., Tabatabaee, H., Jahangiri, M. \& Khavaji, S. (2012). Health effects associated with shift work in 12-hour shift schedule among Iranian petrochemical employees. International Journal of Occupational Safety and Ergonomics, 18/3, 419- 427.

Chu, S. C. (2007). Generating, scheduling and rostering of shift crew-duties: applications at the hong kong international airport. European Journal of Operational Research, 177/3, 1764- 1778.

Ciritcioğlu, C., Akgün, S., Varlı, E. ve Tamer, E. (2017). Kırıkkale Üniversitesi Güvenlik Görevlileri İçin Vardiya Çizelgeleme Problemine Bir Çözüm Önerisi. Uluslararası Mühendislik Araştırma ve Geliştirme Dergisi, 9/2, 1- 23 
De Bruecker, P., Beliën, J., Van den Bergh, J. \& Demeulemeester, E. (2018). A three-stage mixed integer programming approach for optimizing the skill mix and training schedules for aircraft maintenance. European Journal of Operational Research, 267/2, 439- 452.

Demirbilek, T. (2004). Vardiyalı Çalışmanın Kadının Aile ve Sosyal Yaşamına Etkisi”. Sosyal ve Ekonomik Araştırmalar Dergisi, 1/7, 77- 98.

Dinçer, D. (2006) Benzetim Tekniği ile Çağrı Merkezlerinde Vardiya Planlama (Basılmamış Yüksek Lisans Tezi), İstanbul Üniversitesi Fen Bilimleri Enstitüsü, İstanbul.

Ergülen, A., Kazan, H. ve Kaplan, M. (2005). İşletmelerde Dağıtım Sistemi Maliyetleri Minimizasyonu İçin Çözüm Modeli: Bir Firma Uygulaması. Selçuk Üniversitesi Sosyal Bilimler Enstitüsü Dergisi, 13, 163- 172.

Finn, P. (1981). Hhe Effects of Shift Work on The Lives of Employees, Monthly Lab. Rev., 104, 31- 35.

Fry, M. J., Magazine, M. J. \& Rao, U. S. (2006). Firefighter staffing including temporary absences and wastage. Operations research, 54(2), 353-365.

Gerz, M. (2017). Vardiya Usulü Çalışan Ebe ve Hemşirelerde Beslenme Durumunun Saptanması ve Obezite ile İlişkilendirilmesi, (Basılmamış Yüksek Lisans Tezi), Okan Üniversitesi Sağlık Bilimleri Enstitüsü, İstanbul.

Gupta, A., Babu, A., Vrushabhendra, L., Purwar, S. \& Doosa, S. (2018). Shift Scheduling Optimization for PSU Library, 1-16.

Güler, M. G., İdi, K. \& Güler, E. Y. (2013). A goal programming model for scheduling residents in an anesthesia and reanimation department. Expert Systems with Applications, 40/6, 2117- 2126.

Gürbüz, H. ve Cömert, E. (2015). Bakım Planlama Faaliyetlerinde Tamsayılı Doğrusal Programlama ve Bir Uygulama. Karadeniz Sosyal Bilimler Dergisi, 4/7, 101- 122.

Hung, E. W. M., Aronson, K. J., Leung, M., Day, A. \& Tranmer, J. (2016). Shift work parameters and disruption of diurnal cortisol production in female hospital employees. Chronobiology International, 3/8, 1045- 1055.

İlkuçar, M. (2011). Sınav Gözetmenlik Çizelgeleme Probleminin Optimizasyonu ve Bir Uygulama Yazılımı, XIII. Akademik Bilişim Konferansı, 2-4.

İncir, G. (1998). Çoklu Vardiya Çalışmasının Ergonomik Tasarımı, Milli Prodüktivite Merkezi Yayınları, Ankara.

Kassa, B. A. \& Tizazu, A. E. (2013). Personnel scheduling using an integer programming model-an application at avanti blue-nile hotels. SpringerPlus, 2/1, 333.

Katrancı, A. (2018). Tamsayılı Programlama Tekniği ile Vardiya Planlaması: İtfaiye Teşkilatı Örneği, (Basılmamış Yüksek Lisans Tezi), Pamukkale Üniversitesi Sosyal Bilimler Enstitüsü, Denizli.

Kazancı Yabanova, E. (2016). Gece Vardiyasının İşçiler Üzerinde Yarattığı Fizyolojik, Psikolojik, Sosyolojik ve İş Kazası Etkilerine İlişkin Bir Alan Araştırması, (Basılmamış 
Yüksek Lisans Tezi), Çanakkale Onsekiz Mart Üniversitesi Sosyal Bilimler Enstitüsü, Çanakkale.

Korkusuz, R. (2005). Vardiyalı (Postalar Halinde) Çalışma ve Türk İş Hukukundaki Düzenlemesi. Gazi Üniversitesi Hukuk Fakültesi Dergisi, 9/1-2, 1- 18.

Koruca, H. İ. (2010). Simülasyon Destekli Vardiya Planlama Modülü Geliştirilmesi. Gazi Üniversitesi Mühendislik ve Mimarlık Fakültesi Dergisi, 25/3, 469-482.

Küçüksille, E. U. ve Tokmak, M. (2011). Yapay Arı Kolonisi Algoritması Kullanarak Otomatik Ders Çizelgeleme. Journal of Natural \& Applied Sciences, 15(3).

Landsman, D., Ma, H., Knight, J., Gough, K. \& Mishra, S. (2019). A flexible integer linear programming formulation for scheduling clinician on-call service in hospitals, arXiv preprint arXiv:1910.08526.

Leeftink, A. G., Vliegen, I. M. H. \& Hans, E. W. (2019). Stochastic integer programming for multi-disciplinary outpatient clinic planning. Health care management science, 22/1, 53- 67.

Li, J. \& Kwan, R. S. (2003). A fuzzy genetic algorithm for driver scheduling. European Journal of Operational Research, 147/2, 334- 344.

Maenhout, B. \& Vanhoucke, M. (2013), An integrated nurse staffing and scheduling analysis for longer-term nursing staff allocation problems. Omega, 41/2, 485- 499.

Milano M. (2003). Constraint and Integer Programming: Toward a Unified Methodology, Kluwer Academic Publisher, The Netherlands.

Muğaoğlu, T. (1987). Tamsayılı Programlama Problemlerinin Çözümüne Sezgisel Bir Yaklaşım, (Basılmamış Yüksek Lisans Tezi), Erciyes Üniversitesi Sosyal Bilimler Enstitüsü, Kayseri.

Özpeynirci, Ö. \& Ağlamaz, E. (2016). Pharmacy duty scheduling problem. International Transactions in Operational Research, 23(3), 459-480.

Öztürk, A. (2005). Yöneylem Araştırması, Ekin Yayınevi, Bursa.

Pati, A.K., Chandrawanshi, A. \& Reinberg, A. (2001). Shift Work: Consequences And Management, Current Science, 81/1, 32- 52.

Pease, E. C. \& Raether, K. A. (2003). Shift working and wellbeing: a physiological and psychological analysis of shift workers. UW-L J Under Research, 1-5.

Pekşen Arı, Ö. (2013). Vardiyalı Çalışma Düzeninin İş Göreninin İşten Ayrılma Niyetine Etkisi, Bursa'daki Beş Yıldızlı Şehir Otellerinde Bir Uygulama, (Basılmamış Yüksek Lisans Tezi), Afyon Kocatepe Üniversitesi Sosyal Bilimler Enstitüsü, Afyon.

Sadjadi, S. J. \& Esboei, A. A. (2012). A multi-objective programming to increase labor efficiency of a truck hub: a case study. International Journal of Industrial Engineering, 23/2, 155- 162.

Selvi, Y., Özdemir, P. G., Özdemir, O., Aydın, A. ve Beşiroğlu, L. (2010). "Sağlık Çalışanlarında Vardiyalı Çalışma Sisteminin Sebep Olduğu Genel Ruhsal Belirtiler ve 
Yaşam Kalitesi Üzerine Etkisi", Düşünen Adam Psikiyatri ve Nörolojik Bilimler Dergisi, 23/4, 238- 243.

Sezgin, T. (2013). Çalışma Süresi Modellerindeki Değişim ve Çalışan Sağlığı Üzerine Etkileri. Çalışma Dünyası Dergisi, 1/1, 137- 143.

Sierksma, G. (2001). Linear and Integer Programming: Theory and Practice, Marcel Dekker Inc., New York.

Sizane, N. F. \& Van Rensburg, E. (2011). Night shift working mothers: mutual perceptions with adolescent children. Journal of Psychology in Africa, 21/1, 71- 78.

Stevanović, O., Kekić, D., Kónya, V. \& Milenković, M. (2016). The use of linear programming for determining number of fire-fighters on shifts in case of special events. Acta polytechnica hungarica, 13(5), 155-167.

Sungur, B. (2009). Hiyerarşik İşgücü Çizelgeleme Problemi İçin Tamsayılı Programlama Modeli. Dokuz Eylül Üniversitesi İktisadi İdari Bilimler Fakültesi Dergisi, 24/2, 23- 31.

Şengül, Ü. (2010). Tersine Lojistik A $\breve{g}$ Tasarımında Karma Tamsayılı Programlama Modeli ve Ambalaj Atıkları Geri Dönüşümü İçin Bir Uygulama, (Basılmamış Doktora Tezi), Atatürk Üniversitesi Sosyal Bilimler Enstitüsü, Erzurum.

Tan, M., Gan, J. \& Ren, Q. (2019). Scheduling emergency physicians based on a multiobjective programming approach: A case study of west China hospital of sichuan university. Journal of healthcare engineering, 1-9.

Todovic, D., Makajic-Nikolic, D., Kostic-Stankovic, M. and Martic, M. (2015). Police officer scheduling using goal programming. Policing: An International Journal of Police Strategies \& Management, 38/2, 295- 313.

Tütek, H. H. ve Gümüşoğlu, Ş. (2008). Sayısal Yöntemler Yönetsel Yaklaşımlar, Beta Yayınevi, İstanbul.

Varlı, E. ve Eren, T. (2017). Vardiya Çizelgeleme Problemi ve Bir Örnek Uygulama. Bilişim Teknolojileri Dergisi, 10/2, 185- 197.

Wren, A. \& Wren, D. O. (1995). A genetic algorithm for public transport driver scheduling, Computers \& Operations Research, 22/1, 101- 110.

Wu, P., Cheng, J. \& Feng, C. (2019). Resource - constrained emergency scheduling for forest fires with priority areas: An efficient integer-programming approach. IEEJ Transactions on Electrical and Electronic Engineering, 14(2), 261- 270.

Yelek, A., Eren, T., Gür, Ş. ve Alakaş, H. M. (2019). Metro İstasyon İşletme Şeflerinin Vardiyalarının Hedef Programlama ile Çizelgelenmesi. Demiryolu Mühendisliği, 10, 17-30.

Yıldız, A. N., Gedikli, F. G. ve Küçükbiçer, B. (2012). Vardiyalı Çalışmalarda İş Sağlığı ve Güvenliği Konuları, Türkiye İşçi Sendikaları Konfederasyonu Yayını, Aydoğdu Ofset, Ankara. 
Yüksel, İ. (2002). Vardiyalı ve Vardiyasız Çalışan Hemşirelerin İş Güçlüğünün Ayırt Edici Değişkenlerinin Belirlenmesi. Süleyman Demirel Üniversitesi İktisadi ve İdari Bilimler Fakültesi Dergisi, 7/1, 199- 210.

Yüksel, S. (2006). Vardiyalı Çalışma Sistemi ve Türk İş Mevzuatındaki Yeri, (Basılmamış Yüksek Lisans Tezi), Çağ Üniversitesi Sosyal Bilimler Enstitüsü, Mersin. 